\title{
CHARITABLE DONATIONS: EMPIRICAL EVIDENCE FROM BRUNEI
}

\begin{abstract}
Purpose: This paper explores the demographic and psychographic characteristics of Bruneians in relation to charitable donation behaviour.
\end{abstract}

Methodology/Approach: Data were collected via an intercept approach at five major intersections of the central business district in the city of Brunei. Data were analysed using SPSS, with factor analysis being conducted before applying a series of T-tests and ANOVAs.

Findings: Overall there is no relationship between age, income and gender, and donating behaviour. Results show that perceived generosity does not play an important role in Brunei compared to previous studies. The cause of this phenomenon could be due to the influence of the Bruneian culture. That is, the government takes a large responsibility for charitable events in Brunei and for this reason charitable donations from citizens are limited. Analysis also showed the importance of religion in predicting donation behaviour.

Research limitations/implications: Further research in this paper should attempt to make more cross-cultural comparisons of donor characteristics. This would provide a more holistic perspective on donor behaviour and thus assist managerial decisions in the marketing of charities. The effects of religiosity on donation behaviour should be further analysed to ascertain the variances of donation behaviour across cultures with high dominance of religion.

Originality/value: The principal contribution of this paper is that it provides insights into the nuances and characteristics of Bruneians in relation to attitudes and behaviour towards charitable donations. 


\section{INTRODUCTION}

This paper aims to explore the donor demographic and psychographic characteristics Brunei. Further it will conduct comparisons between the studies from United States, United Kingdom, Australia and Brunei to elicit differences in donation behaviour between Western and Asian cultures. Initially, the Bruneian culture will be discussed due to its importance in the charitable donation context. Next the paper presents previous literature on the variables that will be used in the analysis. Following this, an overview of the methodology, key findings and research implications are discussed.

Research in charitable donations over the past decade has focused on planned giving (Brown, 2004; Mohanty, 2011; Bekkers \& Wiepking, 2011; Dvorak \& Toubman, 2013), donor characteristics (Schlegelmilch et al., 1997a), anticipation of intrinsic benefits, such as increased self-esteem, public gratification, satisfaction and fulfilment through meetings one's obligation (Dawson, 1988; Guy \& Patton, 1989; Bruce, 1994; Hibbert \& Horne, 1996; Mohanty, 2011), charitable donation behaviour (Ranganathan \& Henely, 2008; Mohanty, 2011) and helping behaviour (Bendapudi et al., 1996). However, changes in social, political and economic environments in many countries around the world have resulted in declining support to charities (Hibbert and Horne, 1996; Pearce, 2003; Eikenberry, 2005; Spear \& Bidet, 2005; Aiken, 2006; Barraket, 2008). In the United Kingdom alone, Schlegelmilch et al. (1997a) suggested that there has been a declining or at best, stagnant level of donations among it's community. As such, novel ways of marketing strategies, while highly debatable for non-profit organisations have been increasingly employed to generate revenue for charitable organisations (Grace and Griffin 2006). 
Ranganathan and Henley (2008) have reported that charities have to depend more on individual donors and less on the government for funding in order to survive the competition. Hence, an understanding of the individual donor and what motivates them to contribute to charities is of utmost interest to non-profit marketers. While the understanding of donors' characteristics is an important component in attempts to persuade donors, the majority of research in this discipline has been conducted in a "Westernised" culture. There is a clear lack of research in emerging economies such as Asia (e.g. Basil, Ridgway \& Basil, 2008; Lee \& Chang 2007).

This paper aims to explore the characteristics of charitable donations in Brunei, a country that is significantly different in terms of demographics, lifestyle and culture to westernised cultures such as United States, United Kingdom and Australia. The study can be justified by a description of the unique case of Brunei. Brunei Darussalam is a Muslim nation situated in South-East Asia with an estimated relatively small population of about 422,700 (Department of Statistics, 2011). Brunei is governed by a constitutional sultanate that is quite similar to that of the British monarch yet with the significant difference that the sultanate has absolute power over all internal issues of law and governance. One of the most significant issues that will be taken into account within this study is that of Brunei's predominant religion Muslim, which accounts for $70 \%$ of its population. Brunei has a strong image or perhaps more so a stereotype of being very rich, due to the abundance of oil and natural gas in contrast to its small population. With oil exports approximating \$5 billion a year (Department of Statistics, 2011), it is easy to make such an assumption. Although it may be debatable that Brunei and it's people are rich, it is safe to say that Brunei and it's people are not poor. Furthermore, poverty and unemployment levels $(2.7 \%)$ are low (Department of Statistics 2011). This can be highlighted by the fact that the country's gross 
national income per capita is approximately $\$ 31,800$ as of 2009 (The World Bank 2012). This high income per capita is another factor that will be investigated within this paper, as it may bear influence on donation behaviour in Brunei.

Further, the Bruneian government provides for all medical services, subsidizes food, housing and education. Therefore, this may affect charitable donations in Brunei as many services are already paid for by the government. Furthermore, there is a local perception that the relatively small population of Brunei may imply certain detrimental effects to it's business scene. The relatively small market may provide numerous challenges to maintain a strong economy of the country. As a result of this, the current trend of operating charitable organisations as a business (i.e. incorporating the marketing concepts) can ultimately be affected. In addition, the fact that the sultan has such absolute power as well as having being quite "rich" it is common practice for him and the royal family to donate as well as run charities in their name. As Brunei is a constitutional sultanate it can be said that most charities are run by the government. With this said, there is however a number of private charities such as the school and community charitable organisations. This could explain why in Brunei, tax deductions for charitable donations are not allowed unless they are made to institutions approved by the government (KPMG, 2009).

\section{RELEVANT LITERATURE AND HYPOTHESES DEVELOPMENT}

\section{Theory of Giving Behaviour}

Charitable donation or the simple act of giving to others is accredited to the human helping behaviour as explained by the theory of altruism (Webb et al, 2000; Simmons \& Emanuele, 2007; 
Gates and Steane 2007; Dixon 2008; Gates and Steane 2009; Otto \& Bolle, 2011). Comte (1858, $1865,1891)$ first coined the term "altruism", and subsequently scholars have defined altruism in a number of ways. Eisenberg (1986) and Staub (1978) define altruism as prosocial actions intended to benefit others that are not motivated by the desire for self-benefit, Brewer (2003) describes altruism as a cognitive activity to help others, an unconditional and conscious action to improve another person's welfare (Monroe, 1990), an attitude by Frydman et al. (1995), a motive by Sober (1990), a helping behaviour by Schwartz (1970) and a desire to improve another's condition by Karylowski (1982). This empathy-altruism hypothesis from social-psychology studies show that people are not always self-seeking and may be driven by empathy and as such help out others (Eisenberg 1991; Schmidtz 1993; Eveland \& Crutchfield, 2007). Altruistic motivations can be a helping motive and it also include sympathy responding to a request, believing in the cause, and a moral sense of obligation to give back to society (Myers, 1990; Hibbert et al., 2005; Bekkers \& Wiepkin 2011). In essence, this has come to be known in the literature as altruism.

However, the concept of "altruism" is generally thought to be flawed in that it does not sufficiently explain charitable behaviour. Economists have thus offered several other theories in a similar vein to explain giving behaviour; an explanation for "impure altruism" considered here is the psychological "warm glow" model (e.g. Andreoni, 1989; Batson, 1991; Monroe 1996; Paolilli 2009). The "warm glow" model (Andreoni, 1990; Handy \& Katz, 2008) posits that people will experience a "warm glow" from their act of charitable donations (such as sponsoring a child from a distance). This impure altruist model is where donors volunteer their time as well as monetary donation not solely for altruistic notions in providing a public good to society, but also to 
generate a private benefit like a warm glow (Andreoni, 1989; Harbaugh, 1998; Thoits \& Hewiit, 2001; Handy \& Katz, 2008).

\section{Demographic Factors}

Past literature has shown that demographic variables (such as gender, education and income) are effective discriminators between donors and non-donors, due to people's different propensities to engage in charitable behaviour (Riecken \& Yavas 2005; Sargent, 1999; Dvorak \& Toubman, 2013).

While scholars suggest that gender is an important variable when trying to measure the characteristics of charitable donations, it is an issue that is highly inconsistent in terms of the findings (e.g. Croson \& Gneezy, 2009; Dvorak \& Toubman, 2013). Braus (1994) for example found that men made larger average donations and tend to respond favourably to raffle tickets and shop counter collections. Other research found that women gave more frequently and are more likely to devote money and time to charitable causes (Schlegelmilch et al., 1997a; Chang, 2007; Simmons \& Emanuele, 2007; Roberts \& Roberts, 2012; Dvorak \& Toubman, 2013). Moreover, there is also the argument that these issues are blurred by the fact that respondents could be influenced by social desirability factors (Louie \& Obermiller, 2000; Bekkers and Wiepking, 2011).

Age has also been investigated in charitable donation behaviour and once again with some inconclusive results. On the one hand, studies have found that the younger generation are less likely to donate to charities (Smith \& McSweeney, 2007), while others find that age is not a 
factor when considering the characteristics of charitable donors (Louie \& Obermiller, 2000). Other studies have reported that the propensity to donate increases to the age of 65 , at which point donating behaviour starts to taper off and decrease (Danko \& Stanley, 1986; Schlegelmilch \& Tynan, 1989; Schlegelmilch et al., 1997b). These inconsistencies may be attributed to the recent changes in trends of donating to charity, or the country in which the studies were conducted. However, there is some consensus that individuals appear to become more involved with charities through increased donation behaviour as they age (Bennett 2003; Grace and Griffin 2006; Simmons \& Emanuele, 2007; Lee \& Chang 2007; Bennett 2011).

Generally, charitable giving is positively associated with greater levels of income (James and Sharpe, 2007) and wealth (Andreoni \& Scholz, 1998). Schlegelmilch et al. (1997a) and Ostrower (1997) found that those who felt they had more discretionary income tended to give more to charity. This may indicate a personal variable of a "well-off feeling" influences on donation behaviour. However, people with a higher disposable income tend to donate more to charities that are concerned with the environment, third world issues or other global worldwide issues. Radley and Kennedy (1995), and Bennett (2003) emphasise the fact that people with a lower disposable income tend to donate to "more needy people" as they empathise more with them. Bennet (2011) also found contradictory results to other literature, where low-income people tended to donate more than the national average. Therefore, while majority of the literature suggests that higher income begets higher levels of donation, the same may or may not hold true in Brunei.

Past studies have shown that education can have an impact on charitable donation (e.g. Chua, 1999; James, 2008). However, there is also evidence to support that the education level has no 
affect on charitable donations (Schlegelmilch et al., 1997b). The literature further emphasises that individuals who had left school at an earlier age or left school without graduating are more likely to donate to charity in comparison to higher educated donors.

Bennett (2003) has found that the number of children in a household has a direct impact on the likelihood of charitable donations. His research outlines that households with children tend to donate less as compared to households that have no children. Conversely, Lee \& Chang (2007), who conducted a study in Taiwan, found that households with children were more likely to donate. Kanabar (2004) further proposed that in Australia, the "size of the family" is seen as a characteristic that affects the tendency for Australians to donate. Therefore, it is very likely that there are differences in the local family dynamics in various countries that affect and influence the donation behaviour of individuals.

Based on the demographics factors the following hypotheses are depicted:

$\mathbf{H}_{1 \mathbf{a}}$ : There is a significant relationship between gender of donors and charitable donation $\mathbf{H}_{1 \mathbf{b}}$ : There is a significant relationship between age of donors and charitable donation $\mathbf{H}_{1 \mathbf{c}}$ : There is a significant relationship between income of donors and charitable donation $\mathbf{H}_{\mathbf{1 d}}$ : There is a significant relationship between education of donors and charitable donation $\mathbf{H}_{1 \mathbf{e}}$ : There is a significant relationship between family size of donors (number of children) and charitable donation 


\section{Psychographic Factors}

Perceived generosity of self was an important variable in distinguishing between donors and nondonors on their donation intentions (e.g. Westaby, 2005; Bennett, 2011). Schlegelmilch et al. (1997a) found that the more generous donors perceive themselves to be, the more likely they are to donate to charity. In the same vein, it can be assumed that donors are more likely to have higher perceived financial security of self than non-donors. Interestingly, Schlegelmilch et al. (1997a) did not find any evidence to show that individuals who regard themselves as "financially secure" or "not too worried" about their financial state in the future are likely to donate in the future.

The majority of the literature suggests that the more religious individuals perceive themselves to be, the more likely they are to donate to charity (e.g. Ranganathan \& Henley, 2008; Simmons \& Emanuele, 2012). Literature identifies religion as an important issue on the characteristics of charitable donations (Schlegelmilch et al., 1997a; Bennett, 2011; Roberts \& Roberts, 2012). To the authors' knowledge, research into the impact of religion on the donation behaviour of individuals is limited, particularly when investigating donation behaviours of individuals in Muslim countries. There is increasing research into the religious ethicalities of organ donation (e.g. Mohammed, 2012; Randhawa et al., 2010), but research in charitable donations through money or volunteerism is lacking. Schlegelmilch et al. (1997a) notes that the religious donations to Mosques and churches and other religious organisations is one of the fundamental aspects or criteria in the teachings of religion, and is thus an important consideration when evaluating the influence of religiosity on donation behaviour. Ranganathan and Henley (2008) found that religiosity has an impact on the individual's attitudes towards helping others and their attitudes 
towards the charitable organisation, which in turn affects the individual's intentions to donate. This is echoed with research by Simmons and Emanuele (2012), who found that religious people are more likely to donate time and money when compared to those who are not religious. However, Kanabar (2004) replicated research in the Australian context rejected this theory of religion. With this in mind, it is postulated that religion would play a significant role in determining the characteristics of charitable donations in the context of other countries which are heavily governed by Muslim (such as Brunei and Malaysia) and Buddhism (such as Thailand and Taiwan).

The term "world mindedness" has been used in a variety of disciplines such as, political science (Kosterman \& Feshbach, 1989), sociology (Paige et al., 2003), psychology (Smith \& Rosen, 1957), education (e.g. McLeod, 2012) and business (Nijssen \& Douglas, 2008). However, this factor has not been empirically tested, specifically in a charitable donation context. Yet there is evidence that suggests that the world mindedness of an individual may affect their charitable donations. "World minded" individuals are individuals that are described as having a greater knowledge and interest in global issues, as well as people who value the world spirit and its development (Rawwas et al., 1996). Further, the increase in multinational marriages and increasing developments in technology have created more 'hybrid' cultures across the globe and these hybrid cultures are more appreciative towards a sharing world (Lee \& Chen, 2008; Nijssen \& Douglas, 2008; Cleveland et al., 2011). They have a stronger understanding on global welfare and show more empathy to other societies. It suggests that world mindedness is positively related to their willingness to purchase foreign products. 
Based on these findings, the study predicts the following:

$\mathbf{H}_{2 \mathrm{a}}$ : Donors perceive themselves as more generous than non-donors

$\mathbf{H}_{2 \mathbf{b}}$ : Donors perceive themselves as more financially secure than non-donors

$\mathbf{H}_{2 \mathbf{c}}$ : Donors perceived themselves as more religious than non-donors

$\mathbf{H}_{\mathbf{2 d}}$ : Donors who are world minded are more likely to donate more than non-donors.

\section{Perceptions of Charities}

\section{Attitudes towards Charities}

One of the key functions of a charity is to raise funds to enable them to carry out their primary

purpose which is, for the relief of poverty or for the advancement of education, or for the advancement of religion or for other purposes beneficial to the community (Charities Digest, 1995; Knowles et al., 2012). It has also been proposed that people donate to charities that fit with the donors' self image (Polonsky, 2000). As the process of simply donating to charity becomes more elaborate, the more the perceptions on these charitable organisations differ. The brand image of the charity, and the favorability of an individual's overall perception of a charity is significantly related to their choice of a charity and the donor intentions (Bennett, 2003; Smith \& McSweeney, 2007; Michel \& Rieunier, 2012). Schlegelmilch et al. (1997b) has described the changing trends in the level of involvement of the government has within the charity sector. Previous research shows that, the state has been providing charitable donations to the needy (Schlegelmilchet et al., 1997b). However, there has been a change in the sense that charitable donations have been operated more by the private sector now than the government sector. Aside from being attributed to the changing developments in the economy as well as the changes in society, it has accredited to charitable organisations operating more like a 'business'. In fact, the 
benefits from this change meant that donors can requests for more information regarding to what is actually happening with their money (Dart, 2004). At the same time however, it is evident that the general public perceives that there is a need for their government to provide more charitable services and welfare to the needy as well as the fact that the public are donating to charitable donations through "regular tax payments to the state". This would prove to be quite a significant difference when comparing this variable to the Bruneian individual as there are no income taxes implemented in Brunei.

\section{Efficiencies of Charities}

Perceived effectiveness and efficiency of the organisation can affect charitable giving (Bennett, 2003; Sloan, 2009; Szper \& Prakash, 2011). Research shows that higher confidence on charities spending their money wisely increased charitable donations, especially from the wealthy (Szper \& Prkash, 2011). Research in the Netherlands by the Dutch Institute for Public Opinion and Market Research (NIPO, 2003) shows that the large majority of charity supporters would like to know how their donations are spent. This is echoed in the emergence of charity watchdogs in response to scandals where nonprofit resources were abused (Szper \& Prakash, 2011). William (2007) and Iwaarden et al. (2009) confirmed previous studies (such as Schlegelmilch et al., 1997b) that a majority of donors value organisational efficiency and outcomes, and that most donors seek information when making a decision to give. It is a common practice for donors to perceive that all of what they donate will 'reach' the actual cause, yet many other individuals are aware of certain administration costs and fundraising. This ambiguity among the organisational accountability is further blurred as the government involvement with these charity situations is 
lessened. That is, the higher costs or perceived costs that the charitable organisation has, the less likely individuals are willing to donate through that organisation. This is due to the fact that donors want to ensure that most, if not all of their donated funds reach the actual cause (Gugerty \& Prakash 2010; Szper \& Prakash 2011).

Iwaarden (2009) however stated that measuring external effectiveness is different from measuring internal efficiency. That is, an efficient charity can still waste its funds on useless projects, while an inefficient charity can still achieve amazing impact with the few programs with very little funds.

Based on these assumptions, the study hypothesises:

$\mathbf{H}_{3 \mathbf{a}}$ : Donors identify charities to be more efficient than non-donors

$\mathbf{H}_{3 \mathrm{~b}}$ : Donors have a more positive attitude towards charities than non-donors 


\section{METHODOLOGY}

\section{Data Collection}

Data were collected via an intercept approach at five major intersections of the central business district in the city of Brunei. Pedestrians were approached to participate in a self-administered questionnaire. Every fifth individual that crossed a designated spot outside the main entrance of the chosen location was approached to participate. Prior to the data collection, interviewers were trained and instructed on how to administrate the survey instrument and to include respondents with different demographic profiles. The respondents included permanent resident holders, expatriates and even foreigners (Green identity card holders) who have lived in Brunei for at least 5 years. The data collection was conducted over a two week period.

\section{Survey Instrument}

A self administered survey instrument was modelled loosely on Schlegelmilch et al. (1997a) research. Section one comprised of four personality scales, perceived generosity of self, perceived financial security of self, perceived importance of religion and world mindedness. Section two measured the donor's perceived charity efficiency and attitude towards charities. Except for the world mindedness scale which was derived from (Rawwas et al., 1996), all the other scales replicated the measures by Schlegelmilchet et al. (1997a). All these items were measured on a five-point Likert scale with 1 representing "strongly disagree" and 5 representing "strongly agree". The scale items will be discussed in depth in the analysis section of the paper. Section three comprised of demographic information of respondents and a number of classification questions such as if they have donated locally or overseas, and whether they have donated in the last twelve months. 


\section{FINDINGS AND DISCUSSION}

\section{Sample}

In total, 300 useable questionnaires were collected from the Brunei population. Of these 274 respondents had donated before. Data were analysed using SPSS, with factor analysis being conducted before applying a series of T-tests and ANOVAs. Table 1 outlines the demographic profiles of respondents whom participated in the study. There were more females $(53.7 \%)$ than males respondents $(46.3 \%)$. In terms of age, the majority of the respondents fall between the " 26 35 years of age" (34.7\%) and the "less than 25 years of age" (32\%). While this is not ideal for examining the donation behaviour in general, the median age of Bruneians is 27.3 years, with the majority aged between 20 to 54 years and forms about half of the total population at 242,700 people (Department of Statistics, 2011), which is similar to the sample characteristics. In addition, the majority of the respondents are "single" $(52.3 \%)$ or "married" (40\%). In terms of household income, a large number of respondents fall into the "less than $\$ 20,000$ income" bracket (43.3\%). Not surprisingly, a large group of respondents recorded an income bracket higher than that of $\$ 46,000(30.3 \%)$. The results reflect a high level of income per capita as suggested by the literature. Furthermore, the results from the "family size category" were very surprising. It showed that the majority of the respondents fall into the "5+" family size category (39.3\%). Moreover, analysis reports that respondents with "no" children accounted for a majority (45\%). A child was classified as being 16 and under. This indicates that even though the majority of respondents have significantly large families and, there are also households with no children. This suggests that when the children become adults, they take on the responsibility of looking after the entire family. 
**INSERT TABLE 1 HERE** 


\section{Relationship between demographics and charitable donation}

To measure charitable donation, respondents who have donated within the past year are included in the sample. According to the Fisher's Exact test, there was no significant difference between the gender of the respondents and their propensity to donate $(\mathrm{p}=0.538)$. The analysis shows that gender does not influence an individual's tendency to donate, thus, $H_{l}$ a is rejected. The finding coincides with the results from Kanabar (2004) and Schlegelmilch et al. (1997a). $\mathrm{H}_{1 \mathrm{~b}}$ predicts that donors are more likely to be older individuals. However, the chi square test failed to show any significant relationship between age and charitable donations ( $p=0.861)$. Kanabar (2004) has rejected this hypothesis previously and in the same vein, $H_{1 b}$ is also rejected.

An analysis of the relationship between income and charitable donation was conducted to test $\mathrm{H}_{2 \mathrm{c}}$. The result shows no significance $(\mathrm{p}=0.076)$, hence $H_{l} \mathrm{c}$ is rejected.

The Pearson's Chi-square test was used to test the relationship between education and charitable donation. The findings confirm that there was a relationship between these two factors $(\mathrm{p}=$ 0.014). Thus, $H_{1} d$ is accepted. This coincides with Schlegelmilch et al. (1997) research and shows that donors with higher education actually do donate more than donors with lower levels of education.

The Pearson's Chi-square test was used to determine the relationship between family size and charitable donation. The results show that there is no significant relationship between the two variables $(\mathrm{p}=0.205)$. Thus, $H_{l e}$ is rejected and the results reflected Kanabar's (2004) study. 


\section{Relationship between psychographics and charitable donation}

Table 2 illustrates the psychographic profiles of the sample.

\section{**INSERT TABLE 2 HERE**}

Perceived generosity of self was measured using the question, "Compared to other people, do you think you are giving more, less, or about the same to charity?". Results show $48 \%$ respondents were unaware or did not know how generous they were in the act of giving to charity. That is to say that they were not able to decide if they gave more or less than other people in Brunei. This was followed by respondents who said that they give "about the same" (27.3\%), "less" (21.3\%) and "more" (3\%). Furthermore, $\mathrm{H}_{2}$ was tested using a series of t-Test analyses to explore the relationship between psychographics factors and charitable donation. Analysis provides a comparison between respondents that have donated locally or overseas, and whether they have donated in the last twelve months.

A series of T-Test analyses were conducted between perceived generosity of self and donors who have donated in the last year. Results show that there was no significant relationship between perceived generosity of self and donors who have donated locally in the last year $(0.642>0.05)$. Furthermore, there was also no significant relationship identified between donors who had donated overseas within the past year and their perceived generosity of self $(0.884>0.05)$. Similarly, there was also no significant relationship between donors who donate regardless and their perceived generosity of self $(0.562>0.05)$. 
According to the overall results, there is no significant relationship between donors and their perceived generosity of self and therefore this hypothesis is rejected. Hence, $H_{2}$ a is rejected. This result contradicted with the findings from Kanabar's (2004) and Schlegelmilch, Diamantopoulos and Love's (1997a) research. They suggested that donors perceived themselves as more generous than non-donors.

Perceived financial security was measured using "How much do you worry about not having enough money in the future?". Results show that $37.3 \%$ of the total sample population answered "a lot". This was followed by "just a little" with $26.7 \%$, "quite a bit" with $21.7 \%$ and finally, "not at all" with $14.3 \%$.

Results show that there was no significant relationship found between donors who had donated locally within the past year and their perceived financial security $(p=0.672)$. Similarly, no significant relationship was found between donors who had donated overseas within the past year and their perceived financial security $(0.064>0.05)$. Finally, no significant relationship was also indicated between donors who had donated overall and their perceived financial security. $(\mathrm{p}=$ 0.079). Therefore $H_{2 b}$ is rejected. This result coincides with Schlegelmilch et al.'s (1997a) conclusions. However, Kanabar's (2004) study in the Australian context showed donors perceived themselves as more financially secure than non-donors.

When respondents were asked "how important would you say religion is in your life?", over 51\% of respondents recorded "very important". This figure confirms the initial description of Brunei as a heavily religious country due to the strong influences in Muslim. Furthermore, $30.7 \%$ of the 
respondents had declared that religion was still "quite important". The "not very important" and "not important at all" sub variables each recorded $10.7 \%$ and $7 \%$ respectively. The results reveal that religion is a major factor in the lives of the Brunei respondents. Importance of religion in a charitable donation context is measured using an independent t-Test. Results show that the majority of respondents deemed their religion as a 'very important' aspect of their lives (44.7\% of respondents). Further, a large majority indicated that religion is also 'quite important' in relation to their lives ( $24 \%$ of respondents). The findings show the importance of religion in the Bruneian charitable donation context. This notion is further supported by the independent t-Test results. The results indicate that there is a significant relationship between the donors and nondonors' perceived importance of religion $(\mathrm{p}=0.000)$. Hence, $H_{2} \mathrm{c}$ is accepted.

$\mathrm{H}_{2 \mathrm{~d}}$ was tested using an independent t-Test. Result shows that there is no significant relationship between donors and non-donors' world mindedness $(\mathrm{p}=0.291)$. Therefore $H_{2 \mathrm{~d}}$ is rejected. Hence, there are no differences in donors' donation whether they are world minded or non world minded people.

\section{Relationship between perceptions of Charities and charitable donations}

The efficiency of charities was tested through three items concerning the efficiency of home based charities, overseas charities and the acceptable amount spent on costs such as administration and funding costs. An independent analysis was utilized in order to find a significant relationship between a donor's perception towards charity efficiency as opposed to a non-donor's perception. The first variable that was tested was donors who have only donated locally in the past year and their perceptions towards home based charities. There was no 
significant relationship with these variables as $(\mathrm{p}=0.935)$. The relationship between donors who have donated locally and their perception of overseas charities was not significant as well $(\mathrm{p}=$ 0.162). Finally, local donors were tested against the acceptable amount to be spent on costs by charities and it was found that there is a significant relationship between the two variables as $(\mathrm{p}=$ 0.038). Table 3 depicts that donors who had donated to charities locally within the past year do perceive charities to be more efficient than non-donors. The mean response for this variable was $\$ 27.10$ for donors and $\$ 33.80$ for non-donors.

\section{**INSERT TABLE 2 HERE**}

Respondents who have "donated overseas in the past year only" were then tested against their perceptions on the efficiency of charities. There was no significant relationship found for all three items.

Finally, respondents who had donated overall (regardless of locally or overseas) were then tested for a significant relationship with their perceptions on charity efficiency. Firstly, it was found that there was no significant relationship between donors who had donated overall and their perception of efficiency on home based charities as (0.564>0.05). Adversely, there was a significant relationship between the same donors who donated overall and their perception of efficiency of overseas charities as $(0.049<0.05)$. Furthermore, a significant relationship had been found between donors who donated overall and their perception of the acceptable amount to be spent on costs such as administration and other costs $(0.021<0.05)$. 
As we have established a significant relationship between donors who donate overall and their perceptions of perception of efficiency overseas charities, we further analyse their means. We can see from Table 4 below that the overall donors' mean response for the perception of overseas charities was $\$ 56.00$ as compared to non-donors' mean of $\$ 68.10$. Furthermore, from overall donors' perception on the acceptable amount to be spent on costs such as administration and other costs, we can also see that the overall mean of $\$ 27.60$ was lower and thus perceived more efficient than that of non-donors' perception being higher with $\$ 38.50$. With this in mind, as there are significant relationships between donors and their perception of charity efficiency, thus we accept the hypothesis.

\section{**INSERT TABLE 4 HERE**}

The attitude towards charities was measured by asking the respondents 6 items within the questionnaire formulated by Schlegelmilch et al. (1997a). After factor analysis, we find that the 6 items are reduced to 3 factors, matching Schlegelmilch's factors, and thus their relationship will be examined to test for significant relationships. The three factors are: Government responsibility (Governments should help more; Government's basic responsibility to help the needy); Postal appeals (Annoyance at the number of charity appeals; Number of charity appeals through the post are increasing) and National international (Better to donate overseas; National charities are better than overseas). As can be seen in Table 5, there are no significant relationships found between donors and non-donors for each of the attributes. Results indicate that there are no significant differences between donors and non-donors on each dimension of attitude towards charities 
(Government responsibility $p=0.69$, Postal appeals $p=0.95$, Effectiveness of national/international charities $p=0.98)$. Based on these empirical findings $H_{3} \mathrm{~B}$ is rejected.

\section{**INSERT TABLE 5 HERE**}

\section{CONCLUDING COMMENTS}

Overall the findings between the variable of age, income and gender on donating behaviour did not reflect the results of previous studies in the United Kingdom and Australia. Overall there is no relationship between age, income and gender on donation behaviour. This was a major difference between this study and previous studies, it highlighted a key target market and new methods of communication for non-profit marketers in Brunei. That is non-profit marketing campaigns in Brunei should seek donation from the highly educated and educating the nondonors should be a key communication objective for charities in Brunei.

Results show that perceived generosity does not play an important role in Brunei compared to previous studies. The cause of this phenomenon could be due to the influence of the Bruneian culture. That is, the government takes a large responsibility for charitable events in Brunei and for this reason charitable donations from citizens are limited. Thus, that may have impacted on the perceived generosity in the study. Further, from the observations, the study found a large and significant amount of respondents stating that they "don't know" to the perceived generosity of self question. Due to the lack of donation experience and Bruneian's introverted culture nondonors' lack of knowledge may have compounded the impact of perceived generosity. Moreover, 
donation is a part of the everyday life amongst both the Bruneian government and its people. Therefore questioning how much one donates in comparison to another is not an important factor to it's people.

The findings state that there is no difference between donors and non-donors' perception of financial security $\left(H_{2 b}\right)$. Brunei is an oil producer and during this economic environment the country profited from low levels of employment and high levels of prosperity. Hence, that may have contributed to donors and non-donors' attitude on financial security.

Analysis of the results shows that $H_{2} \mathrm{c}$, "importance of religion", plays a significant role in determining a donor in Brunei and the United Kingdom. This hypothesis was rejected however in the Australian context. This result however is not surprising as religion is already an important and integral aspect of the Bruneian lifestyle. It is heavily incorporated in nearly every aspect of the nation. Brunei and its people focus heavily on its religion and also boast that most of their everyday on goings revolves around religion. This implies that charity organisations will most likely need to urge more donations by focusing on mainly the religious aspect of the donation to charity, or the affiliating the organisation with certain religious backgrounds. World mindedness of an individual has no impact on the propensity to donate and thus $\mathrm{H}_{2} \mathrm{~d}$ is rejected. The concept of world mindedness has no impact on charitable donations in an Asian context.

Perceived charity efficiency is shown to be a major factor of charitable donation in Brunei. A significant difference was recorded between donors and non-donors' perceived charity efficiency; that is donors perceived charitable organisations to be efficient and as a result they are likely to 
donate to charities. In the same vein, non-donors perceived charities to be inefficient and assumed that a large amount of the donation will go to administration costs. Hence, they were less likely to donate. The studies from United Kingdom and Australia found no differences, and it suggests that non-donors' knowledge of charities is relatively high. Due to the Bruneian culture, non-donors lack of knowledge about charities' operations. Limited charitable donation experience may have contributed to the lack of knowledge and this is understandable since a large number of charitable events are held by the government. Hence, charitable organisations in Brunei should look to rectify this issue by educating non-donors about their operations. This may increase the likelihood of a charitable donation in Brunei.

Analysis showed no difference between donors and non-donors' attitude towards charities $\left(H_{3 \mathrm{~b}}\right)$. This result was also reflected in the United Kingdom study. However, the Australian study showed that donors' attitude towards charities was more favourable than non-donors. In Brunei, donors and non-donors both believed that the government has a major role in providing social services. Hence, it is part of the reason why no significant differences between donors and nondonors is reported in Brunei.

Brunei has a young population, the latest estimates by United Nations (2010) shows that the median age of a Bruneian citizen is 28.9 years in 2010. Further, as stated previously the median age of Bruneians is 27.3 years in 2011, with the majority aged between 20 to 54 years (Department of Statistics, 2011). Given that $66.7 \%$ of respondents were aged 35 years or younger, the sample provided a fairly reasonable representation of Brunei's population. However, the sample could have been improved by covering a larger spread of respondents from several 
demographic and psychographic backgrounds. This would have given a better cross section of the population for the study.

Brunei does not have many charity appeals through the post and this was reflected by a low mean score $(x=2.84)$ for the second dimension (postal appeals) of attitude towards charities. Hence, that may have an effect on some of the results. Perhaps other dimensions may be explored specifically for countries like Brunei.

As discussed earlier Brunei is an oil rich country, the trading of which is very susceptible to economic changes, and this may have an effect on this research's findings. Hence, a replication study in a different economic environment may show a different result. Further, Brunei is a unique country due to a small population size and rich resources. Therefore the generalisability of the findings is limited even within the Asian context. It will also be interesting to explore the differences between donors and non-donors in other less represented nations that are predominately influenced by other religions and cultures (e.g. Muslim and Buddhism).

\section{REFERENCES}

Aiken, M. (2006). Towards Market or State? Tensions and Opportunities in the Evolutionary Path of Three UK Social Enterprises. In Nyssens, M. (ed), Social Enterprise: At the Crossroads of Market, Public Policies and Civil Society, 259-271. London: Routledge.

Andreoni, J. (1989). Giving with impure altruism: applications to charity and Ricardian equivalence. Journal of Political Economy 97(6): 1447-1458. 
Andreoni, J. (1990). Impure altruism and donations to public goods: a theory of warm-glow giving. Economic Journal 100(401), 464-477.

Andreoni, J. \& Scholz, J. (1998). An econometric analysis of charitable giving with interdependent preferences. Economic Inquiry, 36, 410-428.

Barraket, J. (2008). Strategic issues for the not-for-profit sector. Sydney: UNSW Press.

Basil D.Z., Ridgway N.M., \& Basil M.D. (2008). Guilt and giving: a process model of empathy and efficacy. Psychology and Marketing 25(1), 1-23.

Batson, C. D. (1991). The altruism question: Toward a social psychological answer. Hillsdale, NJ: L. Erlbaum.

Bekkers, R. and Wiepking, P. (2011). A literature review of empirical studies of philanthropy: eight mechanisms that drive charitable giving. Nonprofit and Voluntary Sector Quarterly 40(5), 924-973.

Bennett, R. (2003). Factors underlying the inclination to donate to particular types of charity. International Journal of Non-profit and Voluntary Sector Marketing 8(1), 12-29.

Bennet, R. (2011). Why urban poor donate: A study of low-income charitable giving in London. Nonprofit and Voluntary Sector Quarterly 41(5), 870-891.

Brown, D. W. (2004). What research tells us about planned giving. International Journal of Nonprofit and Voluntary Sector Marketing, 9(1), 86-95.

Bryant, K. W., Jeon-Slaughter, H., Kang, H. and Tax, A. (2003). Participation in philanthropic activities donating money and time. Journal of Consumer Policy 26(1), 43-73.

KPMG. (2009). Asia-Pacific Taxation: Brunei Darussalam. Retrieved from: http://www.kpmg.com/Global/en/services/Tax/regional-tax-centers/asia-pacific-taxcentre/Documents/Asia-Pacific-Taxation/Brunei.pdf. 
"Charities Digest." (1995). Retrieved from http://www.charitychoice.co.uk/.

Chua, V. C. H. \& Chung, M. W. (1999). Tax incentives, individual characteristics and charitable giving in Singapore. International Journal of Social Economics, 26(12), 1492-1504.

Cleveland, M., Erdogan, S., Arikan, G., \& Poyraz, T. (2011). Cosmopolitanism, individual-level values and cultural level values: a cross-cultural study. Journal of Business Research 64(9), 934-943.

Comte, A. (1858), The Catechism of Positive Religion, John Chapman, London (translated by R. Congreve).

Comte, A. (1865), A General View of Positivism, Trubner \& Co., London (translated by J.H. Bridges).

Comte, A. (1891). The Catechism of Positive Religion, 3rd ed., Kegan Paul, London (translated by R. Congreve, 1st published in French 1852, in English tr. 1858).

Croson, R. \& Gneezy, U. (2009). Gender differences in preferences. Journal of Economic Literature 47(2), 1-27.

Danko, W. D. \& Stanley, T. J. (1986). Identifying and reaching the donation prone individual: a nationwide assessment. Journal of Professional Services Marketing, 2(1/2), 117-22.

Dart, R., (2004). Being "Business-Like" in a non-profit organization: a grounded and inductive typology. Nonprofit and Voluntary Sector Quarterly 2004 33: 290

Department of Statistics. (2011). Brunei Darussalam Key Indicators. Retrieved from http://www.depd.gov.bn/download/BDKI2011.pdf.

Dixon, T. (2008). The Invention of Altruism: Making Moral Meanings in Victorian Britain. Oxford University Press. 
Dvorak, T. \& Toubman, S. R. (2013). Are women more generous than men? Evidence from alumni donations. Eastern Economic Journal 39, 121-131.

Eikenberry, A. (2005). Fundraising or promoting philanthropy? A qualitative study of the Massachusetts Catalogue for Philanthropy. International Journal of Nonprofit and Voluntary Sector Marketing 10, 137-149.

Eisenberg, N. (1991). Values, sympathy, and individual differences: toward a pluralism of factors influencing altruism and empathy. Psychological Inquiry 2(2), 128-131.

Eveland, V., \& Crutchfield T. (2007). Understanding why people do not give: strategic funding concerns for AIDS related nonprofits. International Journal of Nonprofit and Voluntary Sector Marketing 12(1), 1-12.

Gates, D.K., \& Steane P. (2007). historical origins and development of economic rationalism. Journal of Management History 13(4), 330-358.

Gates, D.K., \& Steane P. (2009). Altruism - an alternative value in policy formation and decision making. International Journal of Social Economics 36(10), 962-978.

Handy, F. \& Katz, E. (2008). Donating behavior: if time is money, which to give? A preliminary analysis. Journal of Economic Studies, 35(4), 323-332.

Harbaugh, W.T. (1998). What do donations buy? A model of philanthropy based on prestige and warm-glow. Journal of Public Economics 67(2), 269-284.

Hibbert, S. \& Horne, S. (1996). Giving to charity: Questioning the donor decision process. Journal of Marketing 13(4), 4-13.

Horne, S. (1998). Charity Shops in the UK. International Journal of Retail and Distribution Management 26(4), 155-161. 
Iwaarden, J., Wiele, T., Williams, R. \& Moxham, C. (2009). Charities: how important is performance to donors. International Journal of Quality and Reliability Management, 26(1), $5-22$.

James, R. N. (2008). Distinctive characteristics of educational donors. International Journal of Educational Advancement, 8, 3-12.

James, R. N. \& Sharpe, D. L. (2007). The nature and causes of the U-shaped charitable giving profile. Nonprofit and Voluntary Sector Quarterly, 36, 2 (2), 218-238.

Kanabar, T. (2004). Characteristics affecting Charitable Donations in Australia.

Katz, E. \& Rosenberg, J. (2005). An economic interpretation of institutional volunteering. European Journal of Political Economy 21(2), 429-443.

Knowles, S. R., Hyde, M. K., and White, K. M. (2012). Predictors of young people's charitable intentions to donate money: an extended theory of planned behavior perspective. Journal of Applied Social Psychology 42(9), 2096-2110.

Lee, Y. and Chang, C. (2007). Who gives what to charity? Characteristics affecting donation behavior. Social Behavior and Personality 35(9), 1173-1180.

Lee, T. and Chen, F. (2008). Country image effect on Taiwanese consumers' willingness to buy from neighbouring countries. International Journal of Commerce and Management 18(2), 166-183.

Louie, T. and Obermiller, C. (2000). Gender stereotypes and social desireablitity effects on charity donation. Journal of Psychology and Marketing 17(2), 121.

McLeod, J. (2012). Educating for 'world-mindedness': cosmopolitanism, localism and schooling the adolescent citizen in interwar Australia. Journal of Educational Administration and History 44(4), 3398-359. 
Michel, G. and Rieunier, S. (2012). Nonprofit brand image and typicality influences on charitable giving. Journal of Business Research 65, 701-707.

Mohanty, M.S. (2011). Effects of charity on social welfare: A theoretical analysis. Sociology Mind 1(2), 33-35.

Mohammed, G. (2012). Religio-ethical discussions on organ donation among Muslims in Europe: an example of transnational Islamic bioethics. Medicine, Healthcare and Philosophy 15(2), 207-220.

Monroe, K.R. (1990). Altruism and the theory of rational action: Rescuers of Jews in NaziEurope. Ethics 101: 103-122.

Monroe, K.R. (1996). The Heart of Altruism: Perceptions in a Common Humanity. Princeton, Princeton University Press.

Paolilli, A.L. (2009). About the "economic" origin for altruism. Journal of Socio-Economics $38(1), 60-71$.

Parsons, E. (2002). Charity retail: past, present and future. International Journal of Retail and Distribution Management 30(12), 586-594.

Parsons, E. (2004). Charity retailing in the UK: a typology. International Journal of Retail and Consumer Services 11(1), 31-40.

Pearce, J. (2003). Social Enterprise in Anytown. London: Calouste Gulbenkian Foundation.

Polonsky, M. (2000). Helping behaviour models - are they appropriate in Australia? In O'Cass, A. (eds.), Australian \& New Zealand Marketing Academy Conference, Queensland.

Proteau, L. and Wolff, F. (2006). Does voluntary work pay off in the labor market? Journal of Socio-Economics 35(6), 992-1013. 
Rajendran, K. and Rawwas, Y. (1996). The influence of world mindedness and nationalism on consumer evaluation of domestic and foreign products. International Marketing Review, $13(2), 20-38$.

Ranganathan, S. K. and Henley, W. H. (2008). Determinants of charitable donation intentions: a structural equation model. International Journal of Nonprofit and Voluntary Sector Marketing, 13(1), 1-11.

Randhawa, G., Brocklehurst, A., Pateman, R., Kinsella, S., and Parry, V. (2010). Opting-in or opting-out? - The views of the UK's faith leaders in relation to organ donation. Health Policy 96(1), 36-44.

Roberts, J. A. and Roberts, C. R. (2012). Money matters: does the symbolic presence of money affect charitable giving and attitudes among adolescents? Young Consumers: Insight and Ideas for Responsible Marketers 13(4), 329-336.

Schmidtz, D. (1993). Reasons for altruism. In Altruism, edited by Paul E.F., Miller Jr., F.D. and Paul J., 52-68, Cambridge University Press.

Schlegelmilch, B.B., Diamantopoluos, A. and Love, A. (1997a). Characteristics affecting charitable donations: empirical evidence from Britain. Journal of Marketing Practice: Applied Marketing Science 3(1), 14-28.

Schlegelmilch, B.B., Love, A. and Diamantopoluos, A. (1997b). Response to different charity appeals: the impact of donor characteristics on the amount of donations. European Journal of Marketing, 31(8), 548-560.

Schlegelmilch, B. and Tynan, A. (1989). The scope for market segmentation within the charity market: an empirical analysis. Managerial and Decision Economics, 1, 127-134. 
Simmons, W. and Emanuele, R. (2007). Male-female giving differentials: are women more altruistic?. Journal of Economic Studies, 34(6), 534-550.

Simmons, W. O. and Emanuele, R. (2012). Giving patters by religious and non-religious people. Journal of Applied Business Research 28(6), 1243-1251.

Smith, J. R. and McSweeney, A. (2007). Charitable giving: the effectiveness of a revised theory of planned behavior model in predicting donating intentions and behavior. Journal of Community and Applied Social Psychology 17,363-386.

Sloan, M. (2009). The effects of nonprofit accountability ratings on donor behavior. Nonprofit and Voluntary Sector Quarterly 28,220-236.

Spear, R. and Bidet, E. (2005). Social enterprise for work integration in 12 European countries: a descriptive analysis. Annals of Public \& Cooperative Economics 76(2), 195-231.

Spzer, R. \& Prakash, A. (2011). Charity watchdogs and the limits of information-based regulation. Voluntas $21,112-141$.

The Atlas Society. (n.d.) Altruism and Capitalism. Retrieved from: http://www.atlassociety.org/altruism_capitalism.

The World Bank. (2012). GNI per capita, Atlas methos (current US\$). Retrieved from: http://data.worldbank.org/indicator/NY.GNP.PCAP.CD/countries/BN--XR?display=graph. United Nations. (2010). Brunei Darussalam. Retrieved from http://Esa.Un.Org/Wpp/MultipleFigures/Pdf/96.Pdf. 
Table 1: Demographic profile of respondents

\begin{tabular}{|c|c|c|c|}
\hline Demographic profile & Scale & Frequency & Percent \\
\hline \multirow[t]{2}{*}{ Gender } & Male & 139 & 46.3 \\
\hline & Female & 161 & 53.7 \\
\hline \multirow[t]{4}{*}{ Age } & $<25$ & 96 & 32.0 \\
\hline & $26-35$ & 104 & 34.7 \\
\hline & $36-45$ & 52 & 17.3 \\
\hline & $46+$ & 48 & 16 \\
\hline \multirow[t]{6}{*}{ Marital status } & Single & 157 & 52.3 \\
\hline & Engaged & 14 & 4.7 \\
\hline & Defacto & 0 & 0.0 \\
\hline & Married & 120 & 40.0 \\
\hline & Divorced & 7 & 2.3 \\
\hline & Widowed & 2 & 0.7 \\
\hline \multirow[t]{4}{*}{ Household income } & $<20 \mathrm{k}$ & 130 & 43.3 \\
\hline & $20 \mathrm{k}-35 \mathrm{k}$ & 44 & 14.7 \\
\hline & $36 \mathrm{k}-45 \mathrm{k}$ & 35 & 11.7 \\
\hline & $>46 \mathrm{k}$ & 91 & 30.3 \\
\hline \multirow[t]{8}{*}{ Level of education } & 'O' levels & 44 & 14.7 \\
\hline & 'A' levels & 39 & 13.0 \\
\hline & Technical & 36 & 12.0 \\
\hline & college & 3.0 & 1.0 \\
\hline & Certificate & 33 & 11.0 \\
\hline & Diploma & 96 & 32.0 \\
\hline & Degree & 25 & 8.3 \\
\hline & Masters & 24 & 8.0 \\
\hline \multirow[t]{6}{*}{ Family size } & 1 & 19 & 6.3 \\
\hline & 2 & 21 & 7.0 \\
\hline & 3 & 38 & 12.7 \\
\hline & 4 & 52 & 17.3 \\
\hline & 5 & 52 & 17.3 \\
\hline & $5+$ & 118 & 39.3 \\
\hline \multirow[t]{5}{*}{ Number of children } & None & 135 & 45.0 \\
\hline & 1 & 61 & 20.3 \\
\hline & 2 & 46 & 15.3 \\
\hline & 3 & 36 & 12.0 \\
\hline & $4+$ & 21 & 7.3 \\
\hline Total sample size & & 300 & 100.0 \\
\hline
\end{tabular}

